\title{
Evaluation of blended lime-stabilised spent synthetic-based drilling mud and cement for oil well cementing operations
}

\author{
Richard Amorin ${ }^{1}$, Prince Opoku Appau ${ }^{2 \odot *}$, Edward Osei $^{1}$ \\ ${ }^{1}$ Department of Petroleum Engineering, University of Mines and Technology, Tarkwa, Ghana \\ ${ }^{2}$ Research Institute of Enhanced Oil Recovery, China University of Petroleum, Beijing 102249, P. R. China \\ (Received October 25, 2018; revised December 15, 2018; accepted December 20, 2018; available online January 11, 2019)
}

\section{Citation:}

Amorin, R., Opoku Appau, P., Osei, E. Evaluation of blended lime-stabilised spent synthetic-based drilling mud and cement for oil well cementing operations. Advances in Geo-Energy Research, 2019, 3(2): 141-148, doi:

10.26804/ager.2019.02.03.

Corresponding author:

*E-mail: appau.opoku@gmail.com;

2017290109@student.cup.edu.cn

Keywords:

Compressive strength

cement slurry

free fluid

rheology

lime-stabilised mud

\begin{abstract}
:
Most current oil and gas wells are drilled with synthetic-based muds. During drilling, two types of wastes: spent muds and drilled cuttings, are generally generated. Several methods are used in the treatment of these wastes. However, after treatment of these wastes, they are disposed into the environment. Although they seem to be environmentally friendly, greater accumulation may degrade the environment. Nonetheless, some additives used in cement slurry formulation are also present in most of the spent drilling muds, therefore they could be stabilised for reuse in oil and gas wells cementing operations. In recent times, lime is used to stabilise spent synthetic-based drilling mud before disposal or for further treatment. These lime-stabilised muds find use as feedstock of cement kiln, raw material for the production of construction material and wetland restoration materials. This research studies the performance of blended lime-stabilised drilling mud and cement at varied concentrations for oil and gas wells cementing operations. The cement was blended with lime-stabilised mud with concentrations from $0 \%$ to $100 \%$ at a step of $10 \%$ and their properties evaluated. Slurry properties like density, free fluid, rheology and compressive strength results obtained showed that these properties decreased with the increase in percentage blend of the lime-stabilised spent synthetic-based mud. However, it was observed that concentrations of $10 \%$ and $20 \%$ blends of lime-stabilised mud with cement performed better with good potential to be considered in minor cementing works by the industry to help reduce the cost of waste management.
\end{abstract}

\section{Introduction}

Drilling fluid is a complex fluid which comprises several additives. Commonly used drilling fluids should contain a minimum number of additives, this helps to preserve and check the properties of the drilling fluid (Dankwa et al., 2018a). According to Shah et al. (2010), additive type and amount added is dependent on the drilling approach and the nature of the reservoir to be penetrated. The principal functions of drilling fluid include subsurface pressure control, cuttings transport, sealing permeable zone and cooling and lubricating drill string (Nasser et al., 2013). Drilling fluids are widely categorised as water-based drilling fluids (WBDFs), non-aqueous drilling fluids (NADFs) which include diesel, mineral oils, low-toxicity mineral oils (LTMOs) and syntheticbased fluids (SBFs) and Pneumatic (air, mist, foam, gas) drilling fluids (Oghenejoboh et al., 2013). Synthetic-based mud (SBM) is similar to oil-based mMud (OBM) in composition but differs in regards to its makeup since the former base fluid is a synthetic material while the latter is oil. Due to the low aromatic content of SBM, its toxicity is less making it environment-friendly compared to OBM (Shah et al., 2010). SBFs are further divided into four main groups: synthetic hydrocarbons, ethers, esters and acetals. Among the several SBFs, Ester-based fluids biodegrades fully thereby making it the most recommendable SBF. However, the type of SBM to be used is affected by the rheological properties, thermal stability and the filtration of SBM and the type of formations to be drilled through (e.g., whether there are unstable shales present), wellbore complexity (e.g., whether the hole is vertical or directional), casing design, temperature range, permeability and pore pressure analysis (Baba Hamed and Belhadri, 2009; Dhiman, 2012). Among the three main types of drilling fluids, WBDFs are the most widely used fluids because they are easier to formulate, cost less, and environmentally safe (Dankwa et al., 2018b). OBM and SBF are sometimes selected over WBDFs because of their technical advantages in some op- 
erations such as drilling high-temperature and high-pressured wells, shale formations, highly deviated wells, salt caverns and formation of gas hydrates. Despite their high performance, there are limitations to NADFs use. These limitations include their cost, reduced logging quality over WBDFs, the high cost of lost circulation problems, and most important environmental concerns associated with NADFs disposal (Amani et al., 2012).

Drilling oil and gas wells produces vast volumes of two main kinds of wastes: used drilling muds and drilled cuttings (Sharif et al., 2017). The used drilling muds, otherwise known as spent muds are muds which have been used several times in a drilling operation and their properties have become unsuitable for a particular phase of the drilling operation. These spent muds must therefore be treated and disposed in an environmentally safer manner due to their toxicity (Onwukwe and Nwakwadu, 2012). Nonetheless, treatment of drilling waste cost the oil and gas industry huge sums of money since it has to meet stringent standards set by various agencies and bodies responsible for ensuring the safety of the environment before they are discarded. For instance, the United States environmental protection agency (USEPA) and the department of energy (DoE) prohibits discharge of SBFs and other NADFs unless they meet same disposal limits as WBDFs. These include meeting the limits of poly nuclear aAromatic hydrocarbon $(\mathrm{PAH})$ content, toxicity of sediment and rate of biodegradation (Neff et al., 2000). Drilling wastes management is one of the challenges that the petroleum industry is faced with ranging from difficulties in developing technologies to safeguarding a clean and safe environment. Most of the wastes generated during drilling of oil and gas wells have the capacity to negatively affect the environment. Therefore, in order to ensure the safety of the environment during drilling operations, good waste management practices are vital.

There is basically a three-tiered hierarchy for managing drilling waste, namely waste minimisation, recycle/reuse and treatment and disposal (Onwukwe and Nwakwadu, 2012). Several methods or processes have been adopted to treat spent mud before being disposed. These fall majorly into three classes: physico-chemical (leaching, evaporation, stabilisation and solidification), thermal (incineration and desorption) and biological processes (bioremediation) (Chaineau et al., 2000; Barnes and Hartely, 2005; Ball et al., 2012). Some of these methods require very high energy, longer time period and large area requirement for equipment. The USEPA requires a limit of $6.9 \%$ for olefins and $9.4 \%$ for esters drilling fluid retention on cutting before disposal (USEPA, 2001). After treatment, these wastes are disposed into the environment, although they seem to be less toxic, greater accumulation may lead to the degradation of the environment. In recent times, these drilling wastes are sometimes used for beneficial purposes such as production of construction materials, wetland restoration and feedstock to cement kiln but greater percentages are still disposed (Sharif et al., 2017). In the production of construction materials such as the moulding of cement bricks, road construction, large volume of lime is added to the spent drilling mud to stabilise it. This lime is a good bonding material (Holmes, 2012). The oil and gas industries use large volume of cement slurry and these cements are produced from lime-source materials, example limestone and other materials such as clay (Crook, 2006).

The process of placing a cement slurry around the casing and the adjacent formations to the wellbore to accomplish specific functions is termed as oil well cementing. The principal functions of a cementing job includes zonal isolation and segregation, casing and adjacent formation bonding, formation stability and pipe strength movement (Boniface and Appah, 2014). According to Nelson and Guillot (2006), inadequate zonal isolation and or a weak hydraulic seal between the casing, cement and adjacent formation can lead to fluid migration which can be detrimental to the entire cementing operation. There are two common types of cement; ordinary and Portland cement with the latter been the widely used in the oil industry (Piklowska, 2017). The cement slurry is a mixture of cement powder, water and additives (Bett, 2010). Additives are usually included to cement formulations to modify the properties of the slurry and optimise the cement job but not limited to enhancing slurry performance at all well conditions, filtration control, improving cement sheath, cement-casing bond as well as controlling formation fluid influx and migration (BroniBediako et al., 2016). Common additives for oil and gas well cementing operations comprise, heavy weight materials (barite), accelerators (calcium chloride), retarders (lignosulfonates), extenders (bentonite), fluid loss control additives (polymers) and loss circulation additives (fibrous materials), dispersants, friction reducers etc. (Bermudez, 2007; Roshan and Asef, 2010; Shadizadeh et al., 2010).

These additives are also present in most of the spent drilling muds, therefore they can be stabilised for reuse in oil and gas wells cementing operations. Stabilisation is a chemical method aimed at minimising the harmful potential and leachability of waste by transforming the waste product into a less soluble, moveable, or lethal form (Coruh et al., 2013). Lime which is known to be used in stabilising waste mud before disposal or further treatment can be used to condition these spent muds so as to be suitable for the formulation of cement slurry for cementing operations (Tuncan et al., 2000). The use of conditioned spent mud in cement slurry formulation will also save the cost of purchasing new cement additives thereby reducing the total cost of the cementing operation. This study, therefore, seeks to formulate various cement slurry samples by first stabilising a spent synthetic-based drilling mud by adding lime to make it suitable for cement slurry formulation. After stabilisation of the spent synthetic-based mud, different proportions of the lime-stabilised spent synthetic-based mud would be blended with cement to formulate cement slurry. Finally, the physical properties of the newly formulated cement slurry such as compressive strength, fluid loss, density and rheology would be evaluated to ascertain its potential use for oil and gas wells cementing operations.

\section{Materials and experimental procedure}

Table 1. Materials used. 
Table 2. Some components of the spent synthetic-based mud and their effects on the cement slurry.

\begin{tabular}{ll}
\hline Some additives of spent synthetic-based mud & Effects on cement slurry \\
\hline Weighting material (barite) & Increase density and reduces compressive strength \\
Calcium compounds & Decrease density \\
Base oils & Decrease density \\
Clays & Reduces compressive strength, decrease density \\
Salts (calcium chloride) & Act as accelerators but a higher condition they acts as retarders \\
Lime & Acts as retarder and decrease compressive strength \\
\hline
\end{tabular}

Table 3. Some components of the spent synthetic-based mud and their effects on the cement slurry.

\begin{tabular}{llllllllllll}
\hline Test & $\mathrm{A}$ & $\mathrm{B}$ & $\mathrm{C}$ & $\mathrm{D}$ & $\mathrm{E}$ & $\mathrm{F}$ & $\mathrm{G}$ & $\mathrm{H}$ & $\mathrm{I}$ & $\mathrm{J}$ & $\mathrm{K}$ \\
\hline Cement/g & 700 & 630 & 560 & 490 & 420 & 350 & 280 & 210 & 140 & 70 & 0 \\
$(\%)$ & $(100)$ & $(90)$ & $(80)$ & $(70)$ & $(60)$ & $(50)$ & $(40)$ & $(30)$ & $(20)$ & $(10)$ & $(0)$ \\
Lime/g & 0 & 70 & 140 & 210 & 280 & 350 & 420 & 490 & 560 & 630 & 700 \\
$(\%)$ & $(0)$ & $(10)$ & $(20)$ & $(30)$ & $(40)$ & $(50)$ & $(60)$ & $(70)$ & $(80)$ & $(90)$ & $(100)$ \\
\hline
\end{tabular}

\begin{tabular}{ll}
\hline Material & Quantity $(\mathrm{g})$ \\
\hline Waste drilling mud & 3,000 \\
Mix water & 7,084 \\
Cement & 7,084 \\
Lime & 1,500 \\
\hline
\end{tabular}

\subsection{Materials}

A Class $\mathrm{G}$ cement sample and distilled water (mix water) were used for the cement slurry formulation. The waste synthetic-based mud was obtained from a waste management company in Ghana. Table 1 presents the amount of each material used in this study. The spent synthetic-based drilling mud have certain components which in one way or the other may affect some properties of the cement slurry. Some of these components are weighting material (barite), base fluid, organophilic clays, salts, calcium compounds, etc. Table 2 shows some additives present in spent synthetic-based mud and their effect on cement slurry (Broni-Bediako, 2015).

\subsection{Experimental procedure}

\subsubsection{Chemical stabilisation of the waste synthetic-based mud}

The following steps were taken to chemically stabilise the waste synthetic-based drilling mud:

(1) 3,000 g of waste mud was measured with an electronic mass balance into a container with a lid.

(2) 1,500 g of industrial lime was measured and added to the waste mud in the container.

(3) The two materials were mixed thoroughly together to obtain a uniform mixture.

(4) The container was then covered and kept for 21 days.
(5) After 21 days the mixture had compacted, leaving a volume of oil around it.

(6) The oil was then drained from the compacted mixture.

\subsubsection{Formulation of slurry samples}

The procedures used in the formulation of the different slurry samples (A to $\mathrm{K}$ ) were:

(1) concentrations varying from $0 \%-100 \%$ with intervals of $10 \%$ of $700 \mathrm{~g}$ of cement was measured for each sample with an electronic balance.

(2) Concentrations varying from $0 \%-100 \%$ with intervals of $10 \%$ of $700 \mathrm{~g}$ of lime-stabilised waste mud was measured for each sample.

(3) $322 \mathrm{~g}$ of water was weighed for each sample.

(4) The cement, treated mud and water were mixed thoroughly with a speed mixer for 50 seconds. Table 3 shows the amount of cement and lime-stabilised waste mud in each slurry sample.

\subsubsection{Rheological properties measurement}

The rheological properties of the slurries were measured using the following procedure:

(1) The fan viscometer 3,500 model was used to for the test.

(2) Readings were taken at desired speed of 3, 6, 100, 200 and $300 \mathrm{rpm}$.

(3) The plastic viscosity and yield point were computed at the end of the test. The plastic viscosity in centipoise $(\mathrm{cP})$ and yield point values in $\left(\mathrm{lb} / 100 \mathrm{ft}^{2}\right)$ were obtained using Eqs. (1) and (2) (Caenn et al., 2011) respectively.

$$
\text { Plastic Viscosity }(P V)=\left[\theta_{300}-\theta_{100}\right] \times 1.5
$$

$$
\text { Yeild Point }(Y P)=\theta_{300}-P V
$$




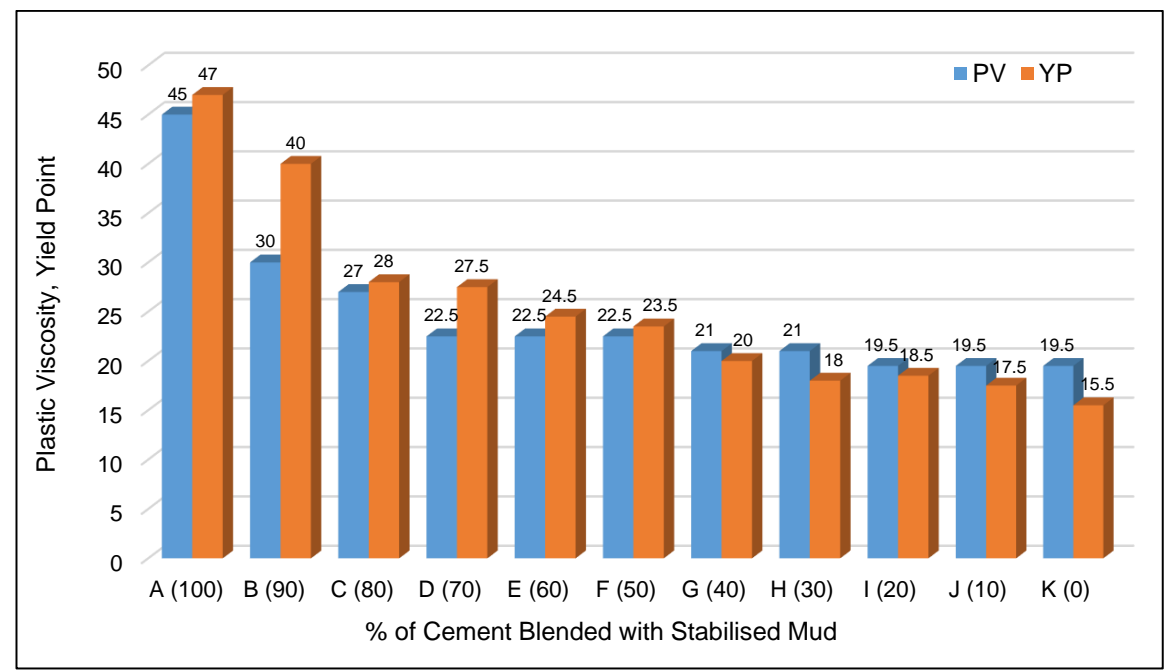

Fig. 1. Plastic viscosity and yield point of the slurry samples at $77^{\circ} \mathrm{F}$.

where $\theta_{300}$ and $\theta_{100}$ are the dial readings at 300 and $100 \mathrm{rpm}$ respectively; rpm is revolution per minute.

\subsubsection{Density measurement}

A hydrometer was used to measure the density of each slurry sample.

\subsubsection{Free fluid measurement}

The following procedures were used to measure the free water of each slurry sample:

(1) $760 \mathrm{~g}$ of each slurry sample was measured into conical flasks.

(2) The conical flasks were allowed to stand for a period of 2 hours.

(3) After 2 hours, the free water on the surface of each slurry sample was collected into a graduated measuring cylinder and measured.

(4) The percentage free fluid obtained at a temperature of $77^{\circ} \mathrm{F}$ was then calculated using Eq. (3):

$$
F F \%=\frac{V_{f f} \times \rho \times 100}{m_{s}}
$$

where, $F F \%$ is the percentage free fluid; $V_{f f}$ is the volume of free fluid in $\mathrm{ml} ; \rho$ is the specific gravity of slurry in $\mathrm{g} / \mathrm{cm}^{3}$; $m_{s}$ is the initial mass of cement slurry.

\subsubsection{Compressive strength of slurry samples measurement}

The compressive strength of the slurry samples were determined using the following procedures:

(1) each slurry sample (A to K) was mixed with the speed mixer.

(2) The samples were poured into cube moulds.

(3) The cube moulds were placed in an atmospheric pressure water bath.

(4) The cubes were then cured for 8 hours at a temperature of $140^{\circ} \mathrm{F}$.
(5) The cubes were then place in the destructive compressive strength tester to determine the compressive strength.

(6) The subsequent pressures were obtained from the pressure gauge and the compressive strengths were computed using Eq. (4):

$$
\text { Compressive Strength }=\frac{\text { Force }(\text { pounds })}{\text { Area }(\text { square inch })}
$$

\section{Results and discussion}

\subsection{Rheology test analysis}

Cement slurry rheology is an indication of the comprehensive interaction between cement particles and water molecules envisaging cementitious suspensions which is imperative for the design, performance (mud removal and optimise slurry placement), and assessment of a primary cementing job (Shahriar, 2011; Hodne, 2017). Therefore, information on the rheological properties of cement prior to its setting will enable better handling and transportation of cement slurries. Quantitative and detailed rheological information can help characterise the rheology (flow) of the cement slurry so as to improve the slurry design. From Fig. 1, it can be observed that, plastic viscosity of the cement slurry decreased as the quantity of lime-stabilised mud was increased. This result is due to the high quantity of lime present in the lime-stabilised mud which tends to decrease the density, and hence the viscosity. The values obtained were less than $100 \mathrm{cP}$ which makes the slurry samples pumpable according to Abbas et al. (2014). It was also observed that, the yield point values of the slurry samples decreased as the amount of lime-stabilised drilling mud increased. This signifies that the slurry samples can flow easily since the yield value gives an indication of the minimum stress required to cause a fluid to flow. 


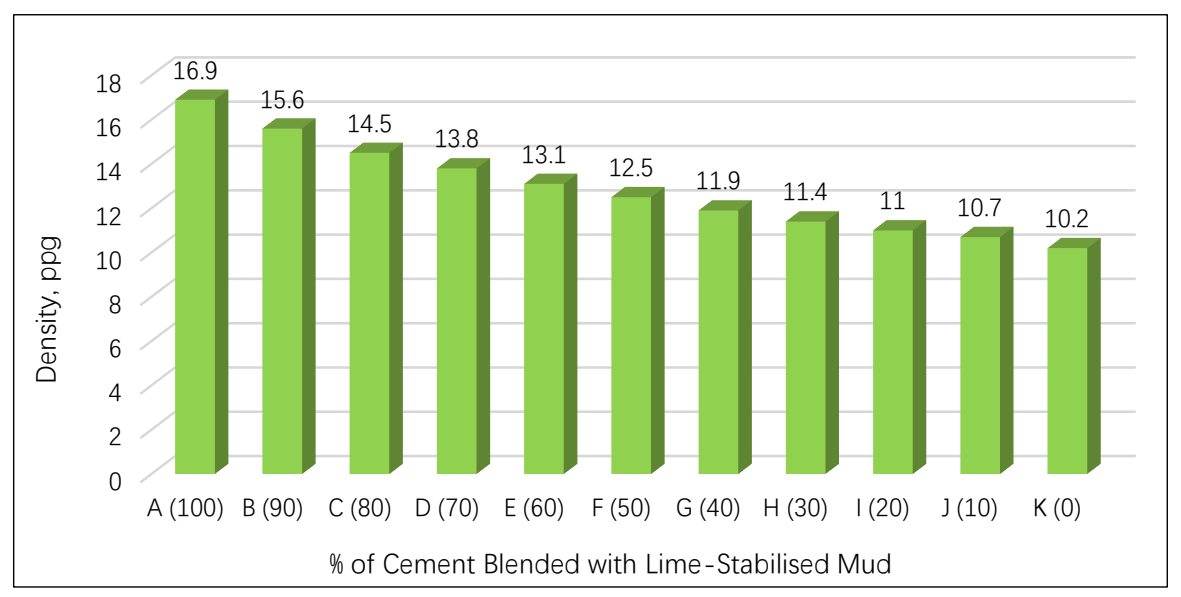

Fig. 2. Density of the slurry samples at $77^{\circ} \mathrm{F}$.

\subsection{Density}

Cement slurry density needs to be sufficiently high to prevent migration of fluids into the well during cementing operation, but not too high to fracture the formation. In general, the density attained by mixing cement with the standard amount of water will be too great for the formation fracture strength, and therefore it will be necessary to lower the slurry density. Reducing the cement density also helps to cut the total cost of the cement slurry. From Fig. 2, it was observed that the values of density of the slurry samples were decreasing as the quantity of lime-stabilised spent mud used to replace the cement increased. The lime-stabilised drilling mud acted as an extender because it reduced the weight of the cement slurry which is beneficial in drilling weak formations and lost circulation zones. This is because of the presence of additives like base oils, calcium compounds, lime and clays present in the lime-stabilised drilling mud. The lime and clay, which were of high percentage in the slurry tend to absorb more of the mix water causing them to expand and therefore increasing the volume of the slurry. Since density and volume are inversely proportional, an increase in volume resulted in a decrease in density. The density of most cement slurry is in the range of 11-18.5 ppg (Kyrilis, 2016) which is in conformance with the results obtained in Fig. 2.

\subsection{Percentage free fluid analysis}

Free water is termed as water which is not desirable for cement hydration. The main aim of the free fluid test is to ascertain the amount of fluid that will be left on top of the cement slurry between the period of slurry placement and setting (Joel, 2009). Normally, operators permit very little values of free water in slurries designed for deeper casing or liner jobs (often zero), mostly in deviated wells or section with gas present. This is because the high free fluid content can cause channelling around the topmost side in the wellbore thereby contributing to annular gas leakage and other resulting problems. It can also result in inadequate corrosion control leading to casing wear and subsequent collapse due to the reaction between water and the formation. High amount of free water is an indication of unstable slurry with settling problems (Normann, 2017). From Fig. 3, it is worth noting that, as the concentration of lime-stabilised mud increased, the percentage of free fluid of the slurry decreased. No percentage free fluid values were recorded for slurry samples H, I, J, and K. Lime and clay have high affinity for water (Kenny and Oates, 2007; Kechouane and Nechnech, 2014) therefore after the hydration of the cement, the excess water was absorbed by the clay and lime. The lime increased the hydration ability of the slurry as reported by Holmes (2012) and Sasanian (2011).

\subsection{Compressive strength analysis}

The integrity of cement to withstand long term-imposed stresses is determined by its compressive strength properties. Compressive strength of cement is mainly determined by either crushing or non-destructive method (Hossain and Al-Majed, 2015). In this study, the crushing method was adopted over the non-destructive method because it gives the exact value of the compressive strength. According to Alp and Akin (2013), greater compressive strength usually depicts low porosity and increased longevity. Consequently, the lifespan of a well can be reduced drastically as casing failure is bound to occur when the compressive strength of the cement sheath is less (Huwel et al., 2014). From Fig. 4, it is worth mentioning that, the values for compressive strength were decreasing as the concentration of the lime-stabilised spent mud used to replace the cement increased after curing the cubes for 8 hours at a temperature of $140^{\circ} \mathrm{F}$. No compressive strength was recorded beyond sample $\mathrm{H}$. The decrease in the compressive strength is due to the presence of clay and lime. Increase in the percentage of lime in the slurry increases the setting time of the slurry thus excess lime acted as a retarder as reported by Yadav and Singh (2015). The minimum compressive strength requirement for cement slurry is 500 psi according to American Petroleum Institute (API) specification (Labibzadeh et al., 2010). This requirement must be achieved before the casing shoe can be drilled out for the next section as it is deemed considerable to support a casing string and permit drilling to continue without the 


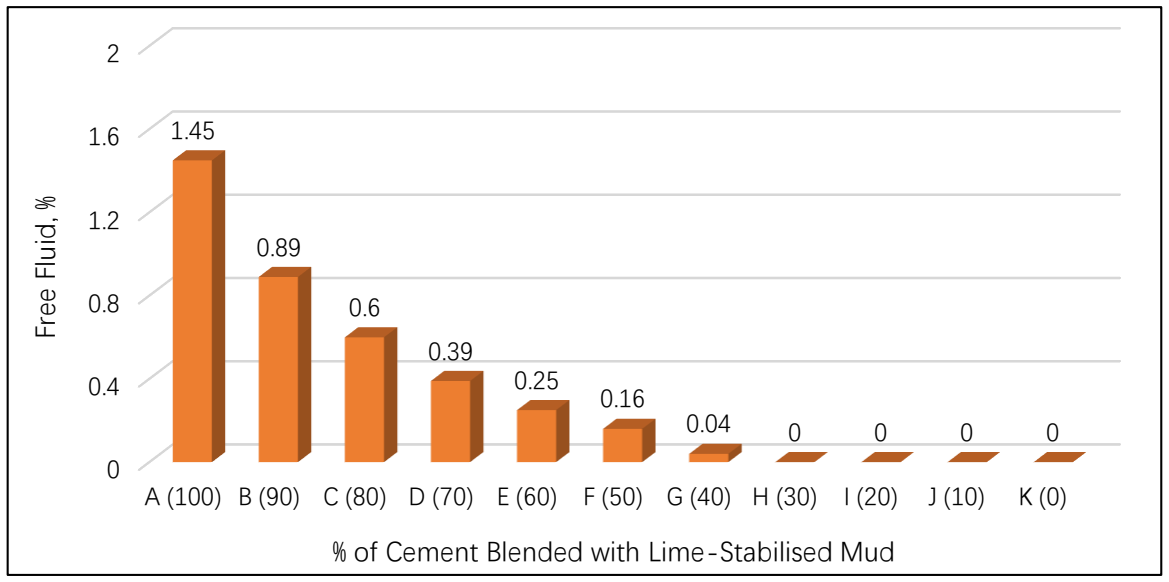

Fig. 3. Percentage free fluid of the slurry samples at $77^{\circ} \mathrm{F}$.

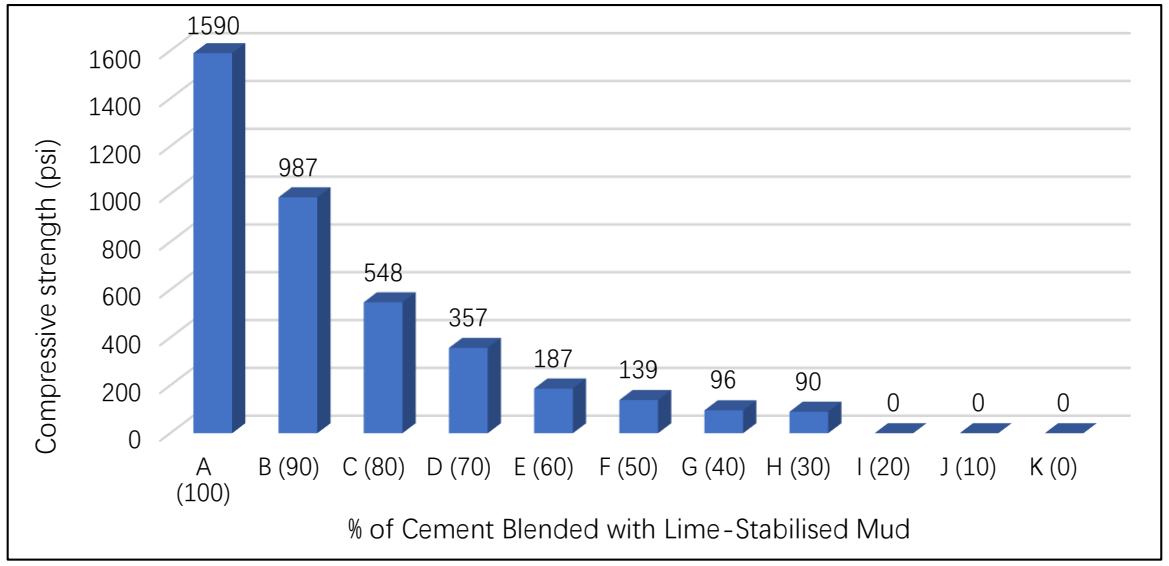

Fig. 4. Compressive strength of the slurry samples cured at $140^{\circ} \mathrm{F}$ for 8 hours.

hardened cement sheath, crumbling due to vibration (Kyrilis, 2016). Apart from sample A, B and C, all the compressive strength of the slurry samples were below this minimum requirement and therefore $\mathrm{D}$ to $\mathrm{K}$ would be recommended for possible high temperature regions.

\section{Conclusions}

The resulting conclusions are drawn in regard to this study:

1) The lime-stabilised spent synthetic-based drilling mud blended well with the local cement but affected the overall integrity of the cement.

2) As the percentage of the lime-stabilised spent syntheticbased drilling mud increased from $0 \%-100 \%$, the compressive strengths and the percentage of free fluid of the slurry decreased.

3) Increase in the quantity of lime-stabilised spent mud in the slurry decreased the plastic viscosity and yield point, which makes the slurry pumpable for a longer period before setting.

4) The density of the slurry decreased as the quantity of lime-stabilised spent mud was increased, this tends to make it a possible extender.

5) Considering the overall tests performed, the lime- stabilised spent synthetic-based cement slurries with concentrations of $10 \%$ and $20 \%$ performed better as compared with higher concentrations. These concentrations presented properties acceptable for field applications, hence they could be used in the cement slurry formulation for minor works by the industry to help reduce the cost of waste management.

\section{Acknowledgement}

The authors would like to thank the University of Mines and Technology, Tarkwa for their support.

Open Access This article is distributed under the terms and conditions of the Creative Commons Attribution (CC BY-NC-ND) license, which permits unrestricted use, distribution, and reproduction in any medium, provided the original work is properly cited.

\section{References}

Abbas, G., Irawan, S., Kumar, S., et al. Characteristics of oil well cement slurry using hydroxypropylmethylcellulose. J. Appl. Sci. 2014, 14(11): 1154-1160.

Alp, B., Akin, S. Utilization of supplementary cementitious materials in geothermal well cementing. Proceedings 
of Thirty-Eighth Workshop on Geothermal Reservoir Engineering, 2013, 1-7.

Amani, M., Al-Jubouri, M., Shadravan, A. Comparative study of using oil-based mud versus water-based mud in HPHT fields. Adv. Pet. Explor. Dev. 2012, 4(2): 18-27.

Ball, A.S., Stewart, R.J., Schliephake, K. A review of the current options for the treatment and safe disposal of drill cuttings. Waste Manage. Res. 2012, 30(5): 457-473.

Barnes, G.R., Hartley, D. Onsite treatment of oily drilling waste in remote areas. Paper AADE-05-NTCE-64 Presented at the AADE 2005 National Technical Conference and Exhibition, Wyndam Greenspoint, Houston, Texas, USA, 5-7 April, 2005.

Bermudez, M. Effect of sugar on the thickening time of cement slurries. Paper SPE113024-STU Presented at the SPE Annual Technical Conference Exhibition, Anaheim California, USA, 11-14 November, 2007.

Bett, E.K. Geothermal well cementing, materials and placement techniques. Geoth. Trai. Programme 2011, 99-130.

Boniface, O.A., Appah, D. Analysis of nigerian local cement for slurry design in oil and gas well cementation. Acad. Res. Int. 2014, 5(4): 176-181.

Broni-Bediako, E. Drilling Engineering. Tarkwa, University of Mines and Technology, 2015.

Broni-Bediako, E., Joel, O.F., Ofori-Sarpong, G. Oil well cement additives: A review of the common types. Oil Gas Res. 2016, 2(1): 1-7.

Caenn, R., Darley, H.C.H., Gray, G.R. Composition and Properties of Drilling and Completion Fluids. Houston, Texas, Gulf Publishing Company, 2011.

Chaineau, C.H., Vidalie, J.F., Geneste, P., et al. Bioremediation of crude oil polluted clay soil in a temperature zone. Paper SPE 61282 Presented at the SPE International Conference on Health, Safety, and the Environment in Oil and Gas Exploration and Production, Stavanger, Norway, 26-28 June, 2000.

Coruh, S., Elevli, S., Ergun, O.N., et al. Assessment of leaching characteristics of heavy metals from industrial leach waste. Int. J. Miner. Process. 2013, 123: 165-171.

Crook, R. Cementing, in Petroleum Engineering Handbook Volume II Drilling Engineering, edited by L.W. Lake and R.F. Mitchell, Richardson, Texas, pp. 369-432, 2006.

Dankwa, O.K., Opoku Appau, P., Broni-Bediako, E. Evaluating the effects of monovalent and divalent salts on the rheological properties of water based mud. The Open Pet. Eng. J. 2018b, 11(1): 98-106.

Dankwa, O.K., Opoku Appau, P., Tampuri, M. Performance evaluation of local cassava starch flour as a secondary viscosifier and fluid loss agent in water based drilling mud. Ghana Min. J. 2018a, 18(2): 68-76.

Dhiman, A.S. Rheological properties \& corrosion characteristics of drilling mud additives. Halifax, Dalhousie University, 2012.

Environmental Protection Agency (EPA). Effluent limitations guidelines and new source performance standards for the oil and gas extraction point source category. OMB Approval under the Paperwork Reduction Act: Technical Amendment, Part IV. 40 CFR Part 9 and 435, Federal
Register, 2001, 66(14): 6850-6919.

Hamed, S.B., Belhadri. M. Rheological properties of biopolymers drilling fluids. J. Pet. Sci. Eng. 2009, 67(3-4): 84-90.

Hodne, H. Rheological performance of cementitious materials used in well cementing. Stavanger, University of Stavanger, 2017.

Holmes, S. An introduction to building limes. United Kingdom, Manchester University, 2012.

Hossain, M.E., Al-Majed, A.A. Fundamentals of Sustainable Drilling Engineering. New Jersey, USA, John Wiley \& Sons, 2015.

Huwel, J.P.E., Faustino, V., Roberts, R. Cement compressive strength development drastically affected by testing procedure. Paper AADE-14-FTCE-22 Presented at the 2014 AADE Fluids Technical Conference and Exhibition held at the Hilton Houston North Hotel, Houston, Texas, USA, 15-16 April, 2014.

Joel, O.F. The secondary effects of lignosulfonate cement retarder on cement slurry properties. ARPN J. Eng. Appl. Sci. 2009, 4(9): 1-7.

Kechouane, Z., Nechnech, A. Characterization of an expansive clay treated with lime: Effect of compaction on the swelling pressure. AIP Conf. Proc. 2014, 1653(1): 020057

Kenny, M., Oates, T. Lime and limestone, In KirkOthmer Encyclopedia of Chemical Technology, (Ed.). New Jersey, USA, John Wiley \& Sons, 2007.

Kyrilis, E. Fly ash-based geopolymer cement as an alternative to ordinary portland cement in oil well cementing operation. Aalborg, Aalborg University, 2016.

Labibzadeh, M., Zahabizadeh, B., Khajehdezfuly, A. Earlyage compressive strength assessment of oil well class $\mathrm{G}$ cement due to borehole pressure and temperature changes. J. Am. Sci. 2010, 6(7): 38-47.

Nasser, J., Jesil, A., Mohiuddin, T., et al. Experimental investigation of drilling fluid performance as nanoparticles. World J. Nano Sci. Eng. 2013, 3(3): 57-61.

Neff, J.M., McKelvie, S., Ayers Jr., R.C. Environmental impacts of synthetic based drilling fluids. New Orleans, Report prepared for MMS by Robert Ayers \& Associates, U.S. Department of the Interior, Minerals Management Service, Gulf of Mexico OCS Region, 2000.

Nelson, E.B., Guillot, D. Well cementing. Texas, USA, Schlumberger, 2006.

Normann, S. Free water in cement slurry: why is it critical?

Oghenejoboh, K.M., Ohimor, E.O., Olayebi, O. Application of re-refined used lubricating oil as base oil for the formulation of oil based drilling mud-a comparative study. J. Pet. Technol. Altern. Fuels 2013, 4(4): 78-84.

Onwukwe, S.I., Nwakwadu, M.S. Drilling wastes generation and management approach. Int. J. Environ. Sci. Dev. 2012, 3(3): 252-257.

Piklowska, A. Cement slurries used in drilling-types, properties, application. World Sci. News 2017, 76: 149-165.

Roshan, R., Asef, M.R. Characteristics of oil well cement slurry using CMC. SPE Drill. Completion 2010, 25: 328-335. 
Sasanian, S. The behaviour of cement stabilized clay at high water contents. London, The University of Western Ontario, 2011.

Shadizadeh, S.R., Kholghi, M., Kassaei, M.H. Experimental investigation of silica fume as a cement extender for liner cementing in Iranian Oil/Gas Wells. Iran. J. Chem. Eng. 2010, 7: 42-66.

Shahriar, A. Investigation on rheology of oil well cement slurries. London, The University of Western Ontario, 2011.

Shah, S.N., Shanker, N.H., Ogugbue, C.C. Future challenges of drilling fluids and their rheological measurements. Paper AADE-10-DF-HO-41 Presented at the 2010 AADE
Fluids Conference and Exhibition, Houston, Texas, USA, 6-7 April, 2010.

Sharif, M.D.A., Nagalakshmi, N.V.R., Redd, S.S., et al. Drilling waste management and control the effects. J. Adv. Chem. Eng. 2017, 7: 166.

Tuncan, A., Tuncan, M., Koyuncu, H. Use of petroleumcontaminated drilling wastes as sub-base material for road construction. Waste Manage. Res. 2000, 18: 489505.

Yadav, S.N., Singh, R.N. Effect of diesel oil, sodium oleate and hydroxyethylcellulose (HEC) as retarders on hydration of lime. Univers. J. Appl. Sci. 2015, 3(2): 13-16. 